NBER WORKING PAPER SERIES

SOCIAL NETWORKS AND ACCESS TO HEALTH CARE AMONG MEXICAN-AMERICANS

Carole Roan Gresenz

Jeannette Rogowski

José J. Escarce

Working Paper 13460

http://www.nber.org/papers/w13460

\author{
NATIONAL BUREAU OF ECONOMIC RESEARCH \\ 1050 Massachusetts Avenue \\ Cambridge, MA 02138 \\ October 2007
}

We thank Sue Polich and Randy Hirscher for their expert help with programming, Elaine Quiter for project management, and Ray Kuntz at the AHRQ Data Center for facilitating our ability to analyze the data. The views expressed herein are those of the author(s) and do not necessarily reflect the views of the National Bureau of Economic Research.

(C) 2007 by Carole Roan Gresenz, Jeannette Rogowski, and José J. Escarce. All rights reserved. Short sections of text, not to exceed two paragraphs, may be quoted without explicit permission provided that full credit, including $\odot$ notice, is given to the source. 
Social Networks and Access to Health Care Among Mexican-Americans

Carole Roan Gresenz, Jeannette Rogowski, and José J. Escarce

NBER Working Paper No. 13460

October 2007

JEL No. I11

\begin{abstract}
$\underline{\text { ABSTRACT }}$
This research explores social networks and their relationship to access to health care among adult Mexican-Americans. We use data from the Medical Expenditure Panel Survey (MEPS) linked to data from the 2000 U.S. Census and other data sources. We analyze multiple measures of access to health care. Measures of social networks are constructed at the ZCTA level and include percent of the population that is Hispanic, percent of the population that speaks Spanish, and percent of the population that is foreign-born and Spanish-speaking. Regressions are stratified by insurance status and social network measures are interacted with individual-level measures of acculturation. For insured Mexican-American immigrants, living in an area populated by relatively more Hispanics, more immigrants, or more Spanish-speakers increases access to care. The social network effects are generally stronger for more recent immigrants compared to those who are better established. We find no effects of these characteristics of the local population on access to care for U.S. born Mexican-Americans, suggesting that similarities in race and language may contribute more to the formation of social ties among individuals who are less acculturated to the U.S. Among the uninsured, we find evidence suggesting that social networks defined by ethnicity improve access to care among recent immigrants. A finding particular to the uninsured is the negative influence of percent of the population that is Hispanic and the percent that is Spanish-speaking on access to care among U.S. born Mexican-Americans. The results provide evidence that social networks play an important role in access to health care among Mexican-Americans. The results also suggest the need for further study using additional measures of social networks, analyzing other racial and ethnic groups, and exploring social networks defined by characteristics other than race, language and ethnicity.
\end{abstract}

Carole Roan Gresenz

RAND Corporation

1200 South Hayes Street

Arlington, Virginia 22202-5050

gresenz@rand.org

Jeannette Rogowski

Department of Health Systems and Policy

University of Medicine and Dentistry of

New Jersey (UMDNJ)

335 George Street, Suite 2200

New Brunswick, NJ 08903

and NBER

rogowsje@umdnj.edu
José J. Escarce

UCLA Med-GIM-HSR

911 Broxton Place

Box 951736

Los Angeles, CA 90095-1736

and NBER

jescarce@mednet.ucla.edu 


\section{Social Networks and Access to Health Care Among Mexican-Americans}

\section{Introduction}

The racial and ethnic composition of neighborhoods appears related to individuals' access to health care, though the mechanism through which this occurs is unclear (Kirby, Taliaferro \& Zuvekas, 2006). Social networks are one means through which the local racial and ethnic composition may influence individuals' use of medical care. Social networks are the contacts individuals have with other people in a group to which they belong (however defined), and it is through these contacts that information flows and norms of behavior are established. In terms of health care, social networks may influence the transmission of information among people about how and where to use care as well as calibrate individuals' ideas about the appropriate use of health services, such as how much and when to see a primary care physician, seek a mammogram, or visit the emergency department.

A substantial body of research extending back decades has confronted the estimation of social network effects in a variety of contexts. Bertrand, Luttmer \& Mullainathan (2000) and Borjas (1995) study the effects of social networks on participation in welfare; McManus (2002) and Montgomery (1991) analyze social networks and labor market outcomes; and Moffitt (2001) summarizes the empirical literature on social network effects of policy interventions, such as the "Moving to Opportunity" program. Other 
research has addressed the relationship between social networks and health outcomes such as disease-specific mortality rates and mental well-being (Kawachi, Colditz, Ascherio, Rimm, Giovannucci, Stampfer \& Willett,1996; Kawachi \& Berkman, 2001; Vogt, Mullooly, Ernst, Pope \& Hollis, 1992; Glass, Mendes de Leon, Seeman \& Berkman, 1997).

Yet the study of social networks has not permeated health economics and health services research to the same degree (Malat, 2006). Some exceptions are Aizer and Currie's (2004) analysis of how use of publicly-provided prenatal services by pregnant women in California is influenced by the behavior of other pregnant women in the same zip code, and two studies that find a relationship between the size of an individual's social network and use of preventive care. Suarez, Lloyd, Weiss, Rainbolt \& Pulley (1994) document greater pap smear and mammogram rates among Mexican-American women in Texas with larger social networks; likewise, Levy-Storms \& Wallace (2003) show the probability of obtaining a mammogram increases with social network size among Samoan women in Los Angeles. No other studies that we are aware of address social networks and their association with access to medical care. ${ }^{1}$ In this paper, we explore the relationship between social networks and access to medical care among MexicanAmericans in the U.S.

\section{Conceptual Background}

\section{Defining the Social Network}


An individual's social network can be characterized by the social ties that he/she establishes (how connected a person is to others) and by the "superstructure" of the network, or the environment in which these connections form (where a more substantial superstructure facilitates social ties) (Hall \& Wellman, 1985). Both social ties and the superstructure of the network may influence the information transmitted and the establishment of norms. The breadth and quality of information flowing among individuals is likely to be primarily determined by the superstructure of the network, and the extent of transmission to a particular individual is likely to be affected by his/her social ties.

Social ties have typically been measured with the number, frequency, and closeness of interactions between an individual and family members, friends, work colleagues, and community/ religious acquaintances (Suarez et al, 1994; Vogt et al, 1992; Kawachi et al, 1996). Measures of the network superstructure capture environmental characteristics that lend themselves to connections among individuals. The well-established socicological principle of "homophily" suggests that contact between similar people occurs at a higher rate than among dissimilar people (Lazarsfeld \& Merton, 1954). McPherson, SmithLovin, \& Cook (2001) assert that geographic proximity is one of the most basic sources of homophily (i.e., people are more likely to have contact with people who live closer to them because of the costs associated with travel—even despite technological advances that could ostensibly mitigate the effects of distance), and that race and ethnicity "create the strongest divides" in the formation of social networks. For example, geographic proximity is the single most important predictor of how often friends get together 
(Verbrugge, 1983), and homophily in race and ethnicity has been shown to influence marital bonds, friendships formed in school, and conversational exchanges (Kalmijn 1998; Marsden 1987, 1988; Shrum, Cheek, \& Hunter, 1988; Schneider, Teske, Roch, \& Marschall, 1997). Language is also a potentially important characteristic of the network superstructure. Alba (1990) finds that people in the U.S. who speak a non-English language at home interact mainly with others who speak that language. Naturally, connections may also form through potentially non-local interactions (such as at a place of work) and age, occupation, religion and other characteristics may also create divides.

\section{Hypotheses}

We hypothesize that the strength of social networks among Mexican-Americans is positively related to access to care. Strong social networks are likely to facilitate the transmission of information about sources of culturally competent care, such as physicians or pharmacy clerks who are bilingual, or, given historically high rates of uninsurance among Mexican-Americans, the availability of providers who offer low-cost or charity care. Derose (2000), for example, finds that the ability of Latino women to obtain care depends heavily on the connections that they establish with bilingual friends, who help them navigate the pathways to care, as well as with bilingual physicians, pharmacy clerks, and medical office administrative staff.

We further hypothesize that the effects of strong social networks may vary for uninsured compared to insured Mexican-Americans. For example, information about providers 
who offer charity or low-cost care may be transmitted more through word of mouth compared to information about providers in an insurance plan, which is usually readily available in the plan's materials. Thus, strong social networks may exert more of a positive influence on access to care for the uninsured compared to the insured.

\section{Data Sources}

We use 1996-2002 MEPS household component survey data linked to data from the 2000 US Census, Area Resource File (ARF), Current Population Survey (CPS), Bureau of Primary Health Care Uniform Data System (BPHC UDS), the Census of Governments, and the Census Bureau's Annual Survey of State and Local Government Finances. MEPS is a nationally representative survey with detailed information on health status and health services utilization. MEPS uses an overlapping panel design in which respondents are interviewed multiple times over a 30-month period to collect data spanning a twoyear period (Cohen, Monheit, Beauregard, Cohen, Lefkowitz, Potter, \& Arnett, 1996/97). Variables describing the local area were derived from the additional data sources listed and linked to MEPS based on respondents' residential zip code. ${ }^{2}$

Our sample includes adult (aged 18 to 64) Hispanic respondents of Mexican descent (Mexican-Americans). We limit the sample to a single national origin to remove potential heterogeneity in the effects of social networks across different subgroups of Hispanics. We chose Mexican-Americans because they represent the largest fraction of Hispanics in the U.S. 
Each observation represents a one-year observation period; individuals can contribute up to two observations in total. We exclude individuals who were ineligible for all or part of the calendar year, such as those who died or were institutionalized during the year. Given the small sample size of Hispanics living in non metropolitan areas, we limit our analysis to those residing in metropolitan statistical areas (MSAs), hereafter referred to as "urban" residents. In total, our data include 14,504 observations from 8,371 respondents.

\section{Methods}

We use multivariate probit regression models to assess the effects of social network on dependent variables that measure access to health care. In our models, we control for a large number of individual and local area characteristics that may influence access to care. We stratify our analyses by insurance status (insured during the year versus uninsured for the entire year) to allow for potential differences in the effects of social networks across these two groups of individuals (as described in Hypotheses).

\section{Dependent Variables}

We estimate models for four dependent variables: (1) whether the person has a "usual source of care," defined as a health care provider where the person usually goes when sick or needing health advice; (2) whether or not the person has an office-based physician or non-physician (e.g., nurse practitioner, podiatrist) visit during a year; (3) whether the 
individual has any prescription drug expenditures during the year; and (4) whether the individual has any medical expenditures or charges during the year. All are $0-1$ dichotomous variables. The "any expenditure" variable is equal to one if an individual has any expenditures for inpatient or outpatient care, pharmaceuticals, durable medical equipment, or other types of care (e.g., home health); in addition, the variable is one if an individual had no expenditures but had positive charges, which indicates receipt of charity (free) care.

\section{Social Network Measures}

We include measures of the superstructure of the social network, but do not directly measure social ties. Including measures of social ties in the models is problematic (even if these measures were available in the MEPS), because they are likely to be endogenous; that is, unobserved characteristics of individuals that influence the number of social ties they have may also influence their propensity to seek or use medical care (such as whether a person is outgoing or introverted). However, because social ties are likely to be influenced by the network superstructure, our analyses with the superstructure variables capture both the direct effects of the network superstructure on access to health care as well as indirect effects that occur through the influence of the superstructure on social ties. From an econometric perspective, our regression models are thus reduced forms. 
We have no measures of the use of health care by individuals in the network (which, if available, would conceivably capture local care-seeking norms). However, the inclusion of these variables would result in the so-called "reflection" problem, which results in biased estimates of network effects (Manski, 1993; Moffitt, 2001). As an alternative, Moffitt (2001) suggests identifying network effects by modeling the effects of exogenous group characteristics on individuals' behavior (as we do), although this type of analysis does not allow for distinguishing the specific mechanism through which the network effects operate.

Following the Conceptual Background, key measures of the superstructure of an individual's social network are the demographic and linguistic characteristics of the local (geographically proximate) population. We construct three alternative social network measures and include each measure in a separate regression. We construct the network measures based on respondents' ZIP Code Tabulation Area (ZCTA) of residence. ${ }^{3} \mathrm{We}$ use ZCTA because it is the lowest level of geography at which we were able to link network measures to individuals.

The first social network measure is based on ethnicity. We include a variable indicating the percentage of the population in the respondent's ZCTA that is Hispanic. ${ }^{4}$ The second social network measure is based on both language and nativity and is the percentage of the local population that is foreign-born and Spanish-speaking. The language restriction is meant to capture the immigrant Hispanic population, since information on number of immigrants by country of origin was unavailable. Language alone forms the basis of the 
third social network measure. We include an indicator of the percentage of the population in the respondent's ZCTA that is Spanish speaking (which is defined as the percentage of individuals who report speaking Spanish at home).

We allow for variability in the effect of social networks on access among MexicanAmericans of varying degrees of acculturation. The local Hispanic/Spanishspeaking/immigrant population may more profoundly affect the formation of social networks individuals who are less acculturated to the U.S. compared to others. We interact each social network measure with an individual-level variable indicating whether the individual was born in the U.S., is foreign-born but has lived in the U.S. for more than five years, or is foreign-born and a recent immigrant.

\section{Individual-Level Explanatory Variables}

At the individual level, we control for socio-demographic characteristics, insurance status, and health status. Socio-demographic controls include education, household structure, gender, age, gender-age interactions, family income as a percent of the poverty

line, language of interview (English or Spanish), ${ }^{5}$ and acculturation. We interpret language of interview as an indicator of an individual's primary language. The acculturation variables are U.S. born (omitted), foreign-born and lived in the U.S. for more than 5 years, and foreign-born and lived in the U.S for less than 5 years. $^{6}$ 
We measure health status with a comprehensive set of variables spanning four domains:

(1) functional, cognitive, and social limitations (a single indicator for any such limitation); (2) vision/hearing problems (single indicator for any such problem, including blindness or deafness); (3) self-rated health, categorized as excellent, very good, good, fair, or poor (an indicator variable for each category); and (4) indicators for chronic conditions. We assessed the presence of 25 chronic conditions (e.g., diabetes, obesity, asthma) and included specific indicator variables for the most frequent conditions as well as a summary indicator for any of the remaining conditions.

For the regressions using the sample of insured individuals, we include an indicator for whether insurance was public or private. All models also included indicator variables for the year of the MEPS data.

\section{Other ZCTA-Level Explanatory Variables}

We include indicators of attributes of the local area that may independently influence access to care: percentage of the population that is black (non Hispanic), percentage that is of another racial minority (non-Hispanic), median family income, population density and the percentage of individuals who are uninsured in each MSA. The last measure is based on a three-year moving average derived from CPS data.

We also include measures of the local health care supply. We include county-level measures of the number of primary care doctors (family practitioners, internists, and 
general practitioners) and the number of hospital beds per thousand people in the county, obtained from the ARF. To capture within county variation in physician supply, we include ZCTA-level variables that measure socio-demographic characteristics that are likely to be correlated with physician location: percent educated at a high school level or beyond and percent of households with income less than the federal poverty line (FPL). We expect relatively high concentrations of low income and less-educated populations to be associated with a smaller local physician supply. Finally, we include two measures of the availability of safety net care for the uninsured. The first is based on BPHC UDS data and captures the number of federally-funded migrant health centers, community health centers, or public housing primary care programs within a five mile radius from the population centroid of the respondent's zip code. The second is the level of local expenditures for health and hospitals based on data from the Census of Governments and the Annual Survey of State and Local Government Finances as a measure of the financial status and general capacity of local safety net providers (Long \& Marquis 1999; Marquis, Rogowski \& Escarce 2004). Expenditures were converted to 2000 dollars using the medical component of the consumer price index and scaled to the low-income population (within 200 percent of the poverty line) in the MSA using data from the March CPS.

\section{Estimation}

We use a probit model for analyses of each of the four dependent variables. All regressions were weighted and adjusted for the complex design of the MEPS survey 
(Cohen et al. 1996/1997; Cohen, DiGaetano, \& Goksel 1999). We stratify all regressions by insurance status (insured versus uninsured).

\section{Results}

Tables 1, 2 and 3 provide descriptive statistics for the dependent and explanatory variables in the analyses.

Tables 4 and 5 present partial regression results for insured and uninsured MexicanAmericans, respectively. Each regression model includes the full set of individual-level explanatory variables listed in Table 3 . However, Tables 4 and 5 show results only for the various social network measures and for the individual-level variables measuring primary language, nativity, and years in the U.S., which are interacted with the social network variables. We report the change in the probability of the dependent variable for a marginal change in the explanatory variable.

In these tables, specification (1) uses the ethnicity-based social network measure (percent of the ZCTA population that is Hispanic); specification (2) uses the social network measure based on nativity and language; and specification (3) uses the language-based social network measure. Each of the social network measures is interacted with the individual-level variables measuring acculturation (US born, foreign-born and lived in the U.S. less than 5 years, foreign-born and lived in the U.S. more than 5 years). We 
begin with discussion of results for Mexican-Americans with insurance and then turn to the uninsured.

Social Networks and Access to Care Among Insured Mexican-Americans (Table 4)

Consistent with previous studies, we find that insured Mexican-Americans whose primary language is Spanish are less likely to have a usual source of care, an office visit, or any medical care expenditures compared to those whose primary language is English. Similarly, foreign-born Mexican-Americans, and particularly those who have lived in the U.S. for a short period of time, are less likely to have a usual source of care, an officevisit, and any medical expenditures compared to U.S.-born Mexican-Americans.

Turning to network effects (Specification 1), a higher percentage of Hispanics in the ZCTA leads to higher probabilities of having a usual source of care and any prescription drug expenditures among immigrants who have lived in the country more than 5 years, and, among more recent immigrants, higher probabilities of any medical care expenditures and any prescription drug expenditures. The effects of the social network on nearly every measure of access to care is significantly greater among immigrants than among the U.S. born $\left(\chi^{2}=4.4\right.$ for usual source of care, $\chi^{2}=5.2$ for any office visit, and $\chi^{2}=3.6$ for any medical expenditure).

We also find that the effects of nativity-based networks differ across individuals depending on where they were born (Specification 2). A higher percentage of the local 
population that is foreign-born increases the probability of having any medical expenditures among recent immigrants and any prescription expenditures among established immigrants. Further, the effect of living in an area with a greater concentration of immigrants is statistically greater among immigrants compared to nonimmigrants for the probabilities of having a usual source of care $\left(\chi^{2}=6.4\right)$, any office visit, $\left(\chi^{2}=3.2\right)$, and any medical expenditure $\left(\chi^{2}=2.8\right)$.

We find a significant positive effect of the percentage of the population who speak Spanish on access to care among both recent and established immigrants, with a higher probability of having any medical expenditures or any prescription drug expenditures among the former and a higher probability of having a usual source of care or any prescription drug expenditures among the latter (Specification 3). The effect of living in an area with more Spanish speakers is statistically greater for immigrants compared to non-immigrants for both the probability of having a usual source of care $\left(\chi^{2}=4.7\right)$ and the probability of having an office-based visit $\left(\chi^{2}=4.6\right.$ for U.S. natives versus recent immigrants; $\chi^{2}=3.9$ for U.S. born versus established immigrants). In addition, the point estimate of the magnitude of the social network effect on access is consistently larger for newer compared to less recent immigrants.

In sensitivity analyses, we tested for a main effect of each social network measure, without interacting it with the variables measuring acculturation (nativity and length of time in the U.S.). We found positive and statistically significant effects of each of the social network measures. For both the percentage of the population that is Hispanic and 
the percentage of the population that is Spanish speaking, these social network measure positively affect the probability of having any prescription expenditures and any medical expenditures. The percentage of the population that is foreign-born and Spanish speaking positively affects the probability of any prescription expenditures.

Social Networks and Access to Care Among Uninsured Mexican-Americans (Table 5)

For uninsured Mexican-Americans, being primarily a Spanish-speaker has negative effects on access to care as measured by the probability of having a usual source of care, and the probability of having any prescription drug expenditures. We again find more limited access to care among recent immigrants compared to U.S. born MexicanAmericans.

Among the uninsured, living in areas populated by Hispanics, Spanish-speakers, or Spanish-speaking immigrants has a deleterious effect on access to care among nativeborn Mexican-Americans. More specifically, we find that for the US born, living in an area with a relatively greater population of Hispanics, Spanish-speakers, or immigrants has a negative effect on the probability of having an office visit. The percentage of immigrants in the local area also has a negative effect on the probability of having any medical expenditures among the U.S. born. 
Echoing the findings for the U.S. born, we find the percentage of the population that is foreign-born reduces the probability of having a usual source of care among immigrants who have lived in the country for more than five years.

By contrast, we find a positive effect of living in an area with more Hispanics or more Spanish-speakers on the probability of having any medical expenditures among recent immigrants who are uninsured.

In a sensitivity analysis, we excluded the interactions between the social network measures and the individual-level acculturation variables. We found negative and statistically significant effects of each of the measures (percentage of the population that is Hispanic, Spanish-speaking, and foreign-born) on the probability of having a usual source of care.

\section{Discussion}

For insured Mexican-Americans, the results are consistent across the range of specifications and measures of access. For Mexican-American immigrants, living in an area populated by relatively more Hispanics, more immigrants, or more Spanish-speakers increases access to care, probably by facilitating the flow of information among people in the local area about where to go for care - or for culturally competent care, more specifically—and what processes to use to get there. The social network effects are 
generally stronger for more recent immigrants compared to those who are better established.

We find no effects of these characteristics of the local population on access to care for U.S. born Mexican-Americans. The finding is natural for the percentage of the local population that is foreign-born, which is only likely to facilitate social networks among individuals who are themselves foreign-born. With regard to the other social network measures, the null findings for the native born Mexican-Americans are consistent with our hypothesis that similarities in race and language may contribute more to the formation of social ties among individuals who are less acculturated to the U.S.

The results for the uninsured further support the notion that social networks may facilitate access to care. We find evidence suggesting that the percentage of the population that is Hispanic fosters social network formation among uninsured Mexican-Americans who are recent immigrants, thereby increasing access to care.

We further find that for uninsured Mexican-Americans who are U.S. born or who have lived in the U.S. for a relatively long period of time, living in areas more heavily populated with immigrants is negatively associated with access to care. These findings are consistent with our hypotheses about social networks and access to care, as the percentage of immigrants is likely to foster bonds primarily among individuals who are themselves immigrants and particularly among those who are more recent immigrants. Compared to the positive effects of the percentage of immigrants in the area on access 
among recent immigrants, we find the logical converse among the U.S. born: the absence of social networks (because in areas with more immigrants there are fewer U.S. born) has negative effects on access.

One of our a priori expectations was that social networks may be more important for the uninsured compared to the insured because of the importance of word-of-mouth communication about providers who will accommodate those limited ability to pay. The evidence suggests this may be the case. Although we find more positive and statistically significant findings for insured immigrants compared to uninsured immigrants, power is more of an issue for the uninsured because the sample size is considerably smaller. The results for U.S. born Mexican-Americans are more revealing. As described, for the U.S. born uninsured, the absence of social networks has a negative effect on access to care. By comparison, we did not find a negative effect (the effect was not statistically different from zero) of the absence of social networks defined by nativity on access among the U.S. born insured, which suggests that the insured may be protected to some degree against the deleterious effects of the absence of social networks.

A finding particular to the uninsured is the negative influence of percent of the population that is Hispanic and the percent that is Spanish-speaking on access to care among U.S. born Mexican-Americans—-factors that we hypothesized would contribute positively to the formation of social networks. One possible explanation is that these population characteristics, rather than aiding in the development of bonds, actually inhibit their formation among the U.S. born. U.S. born Mexican-Americans more strongly 
affiliate with non-Hispanics or non Spanish-speakers, by virtue of having lived in the US their entire lives. For these individuals, it is possible that social networks may be more strongly related to other characteristics (such as occupation or religious participation).

Our study has several limitations. Selection is a potential problem, because people may locate in neighborhoods based on attributes that may themselves be related to access to care. For example, Mexican-Americans who are more distrustful or fearful of U.S. society may choose to live in areas with more ethnically or linguistically similar individuals, and that same distrust and fear may prevent them from seeking health care. In addition, despite our relatively comprehensive set of explanatory variables, unmeasured characteristics of local areas may be correlated with both access to care and our network measures, leading to biased estimates of network effects. The most worrisome unmeasured variable in this regard is the local supply of Spanish-speaking physicians. Finally, it is possible that there are mechanisms other than social networks through which the local racial, ethnic, and linguistic composition influence access to care, although specific competing mechanisms, if they exist, have not been well-articulated.

Nevertheless, the results provide evidence that social networks play an important role in access to health care among Mexican-Americans. The results also suggest the need for further study using additional measures of social networks (for instance, measured at more or less localized geographic levels), analyzing other racial and ethnic groups, and exploring social networks defined by characteristics other than ethnicity, language, and nativity. 


\section{REFERENCES}

Aizer, A. \& Currie, J. (2004). Networks or Neighborhoods? Correlations in the Use of Publicly Funded Maternity Care in California. Journal of Public Economics, 88, 25732585.

Alba, R. D. (1990). Ethnic Identity: The Transformation of White America. New Haven, CT: Yale University Press.

Bertrand, M., Luttmer, E. F. P., \& Mullainathan, S. (2000). Network Effects and Welfare Cultures. The Quarterly Journal of Economics, 115(3), 1019-1055.

Borjas, G. J. (1995). Ethnicity, Neighborhoods, and Human-Capital Externalities. The American Economic Review, 85(3), 365-390.

Cohen, S. B., DiGaetano, R., \& Goksel, H. (1999). Estimation Procedures in the 1996 MEPSHousehold Component (MEPS Methodology Report No. 5. AHCPR PUB. No. 990027). Rockville, Maryland: Agency for Health Care Policy and Research.

Cohen, J. W., Monheit, A. C., Beauregard, K. M., Cohen, S. B., Lefkowitz, D. C., Potter, D. E. B., \& Arnett, R. H. (1996 - 1997). The Medical Expenditure Panel Survey: A National Health Information Resource. Inquiry, 33, 373-389. 
Derose, K. P. (2000). Networks of care: how Latina immigrants find their way to and through a county hospital. Journal of Immigrant Health, 2(2), 79-87.

Glass, T. A., Mendes de Leon, C. F., Seeman, T. E., \& Berkman, L. F. (1997). Beyond single indicators of social networks: a LISREL analysis of social ties among the elderly. Social Science \& Medicine, 44(10), 1503-1517.

Hall, A. \& Wellman, B. (1985). Social networks and social support. In S. Cohen \& S. L. Syme (Eds.) Social Support and Health (pp 23-42). Orlando, FL: Academic Press.

Kalmijn, M. (1998). Intermarriage and homogamy: causes, patterns, trends. Annual Review of Sociology, 24, 395-421.

Kawachi, I. \& Berkman, L.F. (2001). Social ties and mental health. Journal of Urban Health, 78(3), 458-467.

Kawachi, I., Colditz, G. A., Ascherio, A., Rimm, E. B., Giovannucci, E., Stampfer, M. J., \& Willett, W. C. (1996). A prospective study of social networks in relation to total mortality and cardiovascular disease in men in the USA. Journal of Epidemiology and Community Health, 50(3), 245-251.

Kirby, J. B., Taliaferro, G., \& Zuvekas, S. H. (2006). Explaining Racial and Ethnic Disparities in Health Care. Medical Care, 44(5, Suppl.), 64-72. 
Lazarsfeld, P.F. \& Merton, R.K. (1954). Friendship as social process: a substantive and methodological analysis. In M. Berger, T. Abel, C. H. Page (Eds.), Freedom and Control in Modern Society (pp. 18-66). New York: Van Nostrand.

Levy-Storms, L., \& Wallace, S. P. (2003). Use of Mammography Screening Among Older Somoan Women in Los Angeles County: A Diffusion Network Approach. Social Science and Medicine, 57, 987-1000.

Long, S. H., \& Marquis, M. S. (1999). Geographic Variation in Physician Visits for Uninsured Children: The Role of the Safety Net. Journal of the American Medical Association, 281, 2035-2040.

Lynch, J., Due, P., Muntaner, C., \& Smith, G. D. (2000). Social capital--is it a good investment strategy for public health? Journal of Epidemiology and Community Health, 54(6), 404-408.

Malat, J. (2006). Expanding Research on the Racial Disparity in Medical Treatment with Ideas from Sociology. Health, 10(3), 303-321.

Manski, C. (1993). Identification of Endogenous Social Effect: The Reflection Problem. Review of Economic Studies, 60,: 531-542. 
Marquis, M. S., Rogowski, J. A., \& Escarce, J. J. (2004). Recent Trends and Geographic Variation in the Safety Net. Medical Care, 42(5), 408-415.

Marsden, P.V. (1987). Core discussion networks of Americans. American Sociological Review, 52, 122-313.

Marsden, P.V. (1988). Homogeneity in confiding relations. Social Networks, 10, 57-76.

McManus, W. S. (1990). Labor Market Effects of Language Enclaves: Hispanic Men in the United States. The Journal of Human Resources, 25(2), 228-252.

McPherson, M., Smith-Lovin, L., \& Cook, J. M. (2001). Birds of a Feather: Homophily in Social Networks. Annual Review of Sociology, 27, 415-444.

Moffitt, R.A. (2001). Policy Interventions, Low-Level Equilibria, and Social Interactions. In S. N. Durlauf \& H. P. Young (Eds.), Social Dynamics, (pp. 45-82). Washington D.C. and Cambridge, MA: MIT Press and Brookings Institution Press.

Montgomery, J. D. (1991). Social Networks and Labor-Market Outcomes: Toward an Economic Analysis. American Economic Review, 81(5), 1408-1418.

Prentice, J. C. (2005). Neighborhood effects on primary care access in Los Angeles. Social Science \& Medicine, 62(5), 1291-1303. 
Schneider, M., Teske, P., Roch, C., \& Marschall, C. (1997). Networks to nowhere: segregation and stratification in networks of information about schools. American Political Science Review, 41, 1201-1223.

Shrum W., Cheek, N.H. Jr., \& Hunter S.M. (1988). Friendship in school: gender and racial homophily. Social Education, 61, 227-39.

Suarez, L., Lloyd, L., Weiss, N., Rainbolt, T., \& Pulley L., (1994). Effect of social networks on cancer-screening behavior of older Mexican-American women. Journal of the National Cancer Institute, 86(10), 775-779.

Verbrugge, L.M. (1983). A research note on adult friendship contact: a dyadic perspective. Social Forces, 62, 78-83.

Vogt, T. M., Mullooly, J. P., Ernst, D., Pope, C. R., \& Hollis, J. F. (1992). Social networks as predictors of ischemic heart disease, cancer, stroke and hypertension: incidence, survival and mortality. Journal of Clinical Epidemiology, 45(6), 659-666. 


\section{ENDNOTES}

${ }^{1}$ Other studies have explored the effect of social capital on health and access to health care (e.g., Lynch, Due, Muntaner \& Smith, 2000; Prentice, 2005), but the concept of social capital is distinct from that of social networks. Social capital often refers to the level of trust and reciprocity in the community and may influence access to care by affecting individuals' trust in community physicians, psychosocial well-being (and consequently individuals inclination to obtain care), and/or functional support (e.g. a neighbors willingness to provide childcare during a medical appointment). By comparison, social networks capture the role of information and norms on access to care.

${ }^{2}$ No geographic identifiers other than region and MSA are available on the public use MEPS. Social and Scientific Systems (SSS), operating through a contract with the Agency for Healthcare Research and Quality (AHRQ), linked local area characteristics to individual respondents and the resulting data file, stripped of geographic identifiers, was available for our use on-site at the AHRQ Data Center.

${ }^{3}$ ZCTAs were developed by the U.S. Census Bureau for the Census 2000. They are generalized area representations of U.S. Postal Service ZIP Code service areas. In many cases, ZCTA and zip code are the same.

${ }^{4}$ Ideally, we would be able to capture the percentage of the population that is of Mexican origin, but this measure was unavailable at the population level. 
${ }^{5}$ The only variable available for measuring individual-level language is language in which the MEPS interview was completed. We create a variable that is zero if the MEPS interview was completely in English and positive if the interview was wholly or partly in Spanish. A limitation is that this measure does not allow us to distinguish bilingual from monolingual individuals.

${ }^{6}$ We include dummy variables for observations missing either years in the U.S. or nativity. 
Table 1

Dependent Variables:

Descriptive Statistics for the Analytic Sample

\begin{tabular}{lcc}
\hline & Mean & Std \\
\hline Dependent Variables & & \\
Usual source of care & 0.54 & $(0.005)$ \\
Any office-based physician visits & 0.51 & $(0.005)$ \\
Any prescription drug expenditures & 0.47 & $(0.005)$ \\
Any expenditures or charges & 0.59 & $(0.005)$ \\
\hline
\end{tabular}


Table 2

Social Network Measures, Socio-Demographic Characteristics of the Population, and Health Care Supply Measures: Descriptive Statistics for the Analytic Sample

\begin{tabular}{|c|c|c|}
\hline & Mean & $\begin{array}{l}\text { Std } \\
\text { Err }\end{array}$ \\
\hline \multicolumn{3}{|l|}{ Social Network Measures } \\
\hline Percent of the population that is Hispanic & 0.42 & $(0.003)$ \\
\hline Percent of the population that is foreign-born and speaks & & \\
\hline Spanish $\quad 1-1$ & 0.19 & $(0.001)$ \\
\hline Percent of the population that speaks Spanish & 0.37 & $(0.003)$ \\
\hline \multicolumn{3}{|l|}{$\begin{array}{l}\text { Other Socio-Demographic Characteristics of the Local } \\
\text { Area }\end{array}$} \\
\hline Percent of the population with high school or more education & 0.67 & $(0.002)$ \\
\hline Percent of the population with family income < FPL & 0.16 & $(0.001)$ \\
\hline Population density (thousand people per square mile) & 5.20 & $(0.064)$ \\
\hline Percent of the population with no insurance & 0.24 & $(0.001)$ \\
\hline Percent of the population that is black & 0.08 & $(0.001)$ \\
\hline Percent of the population that is another racial minority & 0.30 & $(0.002)$ \\
\hline Median family income (in $\$ 10,000$ s) & 4.35 & $(0.016)$ \\
\hline \multicolumn{3}{|l|}{ Health Care Supply Measures } \\
\hline Physicians per 1000 in the county & 0.56 & $(0.002)$ \\
\hline Hospital beds per 1000 in the county & 2.40 & $(0.012)$ \\
\hline Number of federally-funded safety net providers w/ in 5 miles & 2.46 & $(0.055)$ \\
\hline $\begin{array}{l}\text { Local health/ hospital spending per low income population (in } \\
\$ 100 \text { s) }\end{array}$ & 3.25 & $(0.009)$ \\
\hline
\end{tabular}


Table 3

Individual-Level Independent Variables:

Descriptive Statistics

\begin{tabular}{|c|c|c|c|c|c|}
\hline Characteristic & Mean & Std Err & Characteristic & Mean & Std Err \\
\hline Age 18-24 years & 0.19 & $(0.004)$ & Excellent self rated health & 0.25 & $(0.005)$ \\
\hline Age 25-34 years & 0.33 & $(0.005)$ & Very good self rated health & 0.30 & $(0.005)$ \\
\hline Age 35-44 years & 0.25 & $(0.004)$ & Good self-rated health & 0.31 & $(0.005)$ \\
\hline Age $45-64$ years & 0.15 & $(0.003)$ & Fair self-rated health & 0.11 & $(0.003)$ \\
\hline Age 55-64 years & 0.08 & $(0.003)$ & Poor self-rated health & 0.03 & $(0.001)$ \\
\hline Less than high school & 0.47 & $(0.005)$ & Excellent self-rated mental health & 0.37 & $(0.005)$ \\
\hline High school graduate or GED & 0.30 & $(0.005)$ & Very good self-rated mental health & 0.30 & $(0.005)$ \\
\hline Some college & 0.15 & $(0.004)$ & Good self-rated mental health & 0.28 & $(0.005)$ \\
\hline College graduate & 0.08 & $(0.003)$ & Fair or poor self-rated mental health & 0.06 & $(0.002)$ \\
\hline \multirow[t]{2}{*}{ Female } & 0.48 & $(0.005)$ & Vision problem/blindness & 0.04 & $(0.002)$ \\
\hline & & & Hearing problem/ deafness & 0.03 & $(0.002)$ \\
\hline Married & 0.57 & $(0.005)$ & Cognitive limitation & 0.02 & $(0.001)$ \\
\hline Divorced/separated & 0.10 & $(0.003)$ & Social limitation & 0.02 & $(0.001)$ \\
\hline Widowed & 0.02 & $(0.001)$ & Functional limitation & 0.04 & $(0.002)$ \\
\hline Never married & 0.31 & $(0.005)$ & & & \\
\hline \multirow[t]{2}{*}{ Family size } & 3.94 & $(0.020)$ & Anxiety & 0.02 & $(0.001)$ \\
\hline & & & Arthropathies & 0.04 & $(0.002)$ \\
\hline Uninsured & 0.37 & $(0.005)$ & Asthma & 0.02 & $(0.001)$ \\
\hline \multirow[t]{2}{*}{ Public insurance } & 0.11 & $(0.003)$ & Depression & 0.05 & $(0.002)$ \\
\hline & & & Diabetes & 0.05 & $(0.002)$ \\
\hline Income <1x FPL & 0.20 & $(0.004)$ & Disease of lipid metabolism & 0.03 & $(0.002)$ \\
\hline Income 1-2x FPL & 0.30 & $(0.005)$ & Hypertension & 0.06 & $(0.002)$ \\
\hline Income $2-4 x$ FPL & 0.33 & $(0.005)$ & Migraine & 0.02 & $(0.002)$ \\
\hline Income $>4 x$ FPL & 0.16 & $(0.004)$ & Other chronic condition & 0.03 & $(0.002)$ \\
\hline \multirow[t]{2}{*}{ Interview in Spanish } & 0.44 & $(0.005)$ & 1996 & 0.12 & $(0.003)$ \\
\hline & & & 1997 & 0.12 & $(0.003)$ \\
\hline U.S. born & 0.46 & $(0.005)$ & 1998 & 0.13 & $(0.004)$ \\
\hline Foreign-born, lived in US $>5$ years & 0.33 & $(0.005)$ & 1999 & 0.14 & $(0.004)$ \\
\hline Foreign-born, lived in US<5years & 0.06 & $(0.002)$ & 2000 & 0.15 & $(0.004)$ \\
\hline Foreign-born, missing years in US & 0.10 & $(0.003)$ & 2001 & 0.17 & $(0.004)$ \\
\hline Missing foreign-born & 0.05 & $(0.003)$ & 2002 & 0.17 & $(0.004)$ \\
\hline
\end{tabular}


Table 4

Social Networks And Access To Care Among Insured Mexican Americans

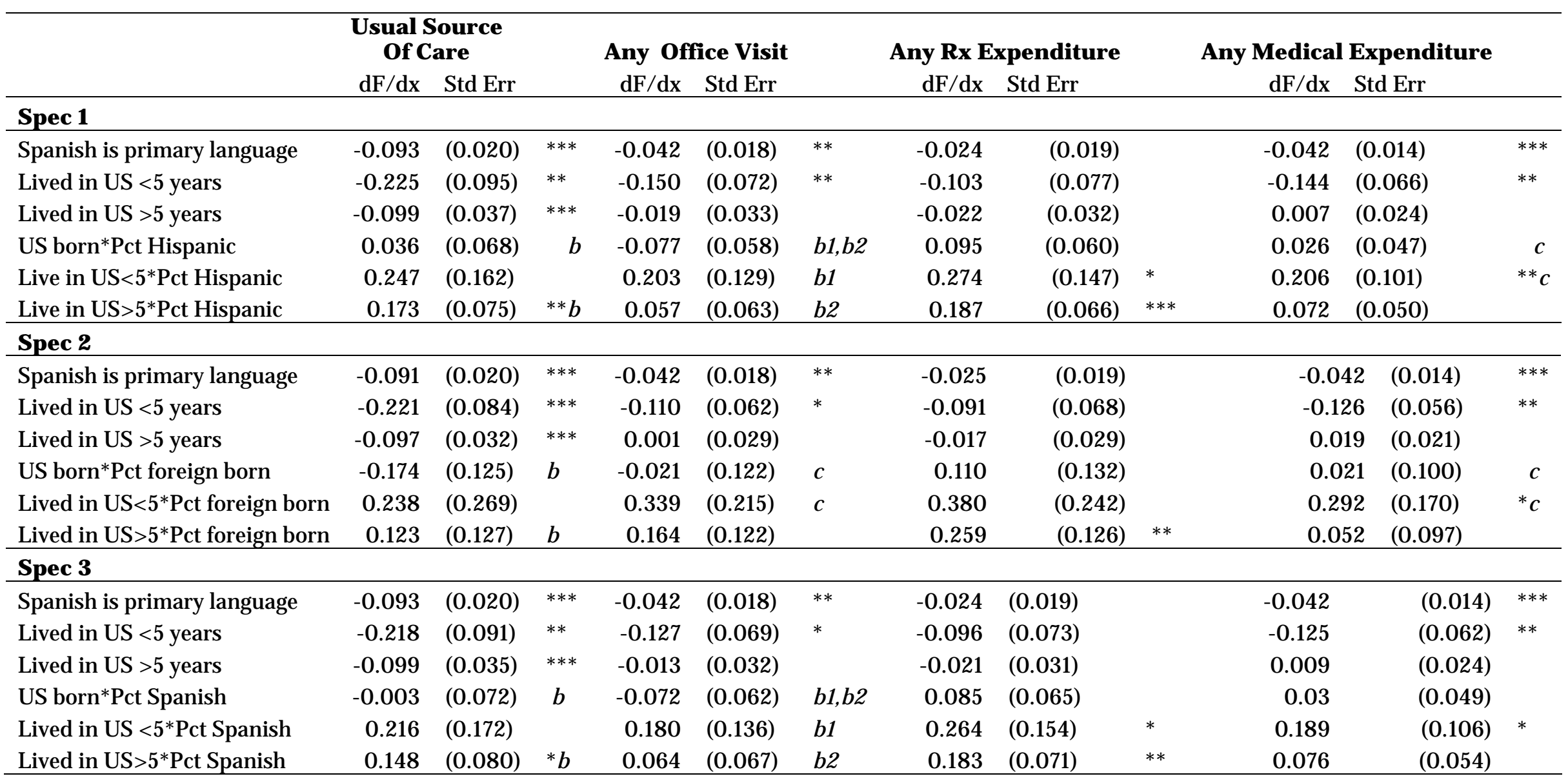

Table Notes: Standard errors in parentheses. Stars indicate statistical difference of coefficient from zero; letters indicate statistical difference between coefficients. *** indicates significance at the .01 level, ** at the .05 level and * at the .10 level. Letters are included next to each element of the comparison pair, with a indicating a difference at the .01 level, $\mathrm{b}$ indicating significantly different at the .05 level, and ${ }^{\mathrm{c}}$ indicating significantly different at the .10 level. 
Table 5

Social Networks And Access To Care Among Uninsured Mexican Americans

\begin{tabular}{|c|c|c|c|c|c|c|c|c|c|c|c|c|}
\hline & \multicolumn{2}{|c|}{$\begin{array}{c}\text { Usual Source } \\
\text { of Care }\end{array}$} & & \multicolumn{2}{|c|}{ Any Office Visit } & & \multicolumn{2}{|c|}{$\begin{array}{c}\text { Any Rx } \\
\text { Expenditure }\end{array}$} & & \multicolumn{2}{|c|}{$\begin{array}{l}\text { Any Medical } \\
\text { Expenditure }\end{array}$} & \\
\hline & $\mathrm{dF} / \mathrm{dx}$ & Std Err & & $\mathrm{dF} / \mathrm{dx}$ & Std Err & & $d F / d x$ & Std Err & & $\mathrm{dF} / \mathrm{dx}$ & Std Err & \\
\hline \multicolumn{13}{|l|}{ Spec 1} \\
\hline Spanish is primary language & -0.115 & $(0.026)$ & $* * *$ & -0.025 & $(0.024)$ & & -0.046 & $(0.025)$ & $*$ & -0.040 & $(0.026)$ & \\
\hline Lived in US $<5$ years & -0.044 & $(0.070)$ & & -0.097 & $(0.054)$ & $*$ & -0.032 & $(0.059)$ & & -0.118 & $(0.059)$ & $*$ \\
\hline Lived in US $>5$ years & 0.051 & $(0.054)$ & & -0.058 & $(0.044)$ & & 0.026 & $(0.043)$ & & -0.038 & $(0.045)$ & \\
\hline US born*Pct Hispanic & 0.026 & $(0.086)$ & & -0.224 & $(0.083)$ & *** a1,a2 & -0.109 & (0.075) & $\mathrm{b}$ & -0.134 & $(0.085)$ & $a, b$ \\
\hline Live in US $<5 *$ Pct Hispanic & -0.027 & $(0.134)$ & & 0.105 & $(0.117)$ & a1 & 0.111 & $(0.116)$ & $\mathrm{b}$ & 0.217 & $(0.126)$ & $* \mathrm{a}$ \\
\hline Live in US $>5 *$ Pct Hispanic & -0.030 & $(0.083)$ & & -0.018 & $(0.074)$ & a2 & -0.056 & (0.075) & & 0.033 & $(0.083)$ & $\mathrm{b}$ \\
\hline \multicolumn{13}{|l|}{ Spec 2} \\
\hline Spanish is primary language & -0.111 & $(0.026)$ & $* * *$ & -0.022 & $(0.024)$ & & -0.045 & $(0.026)$ & $*$ & -0.036 & $(0.026)$ & \\
\hline Lived in US $<5$ years & -0.042 & $(0.063)$ & & -0.046 & $(0.054)$ & & -0.005 & $(0.057)$ & & -0.092 & $(0.056)$ & \\
\hline Lived in US $>5$ years & 0.060 & $(0.046)$ & & -0.016 & $(0.040)$ & & 0.039 & $(0.038)$ & & -0.030 & $(0.041)$ & \\
\hline US born*Pct foreign born & -0.223 & $(0.165)$ & & -0.296 & $(0.157)$ & $*$ b1, b2 & -0.149 & $(0.150)$ & $\mathrm{C}$ & -0.407 & $(0.166)$ & $* * a, b$ \\
\hline Lived in US $<5 *$ Pct foreign born & -0.337 & $(0.225)$ & & 0.169 & $(0.183)$ & b1 & 0.184 & (0.190) & $\mathrm{C}$ & 0.221 & $(0.199)$ & $\mathrm{a}$ \\
\hline Lived in US $>5 *$ Pct foreign born & -0.366 & $(0.140)$ & $* * *$ & 0.012 & $(0.124)$ & $\mathrm{b} 2$ & -0.066 & $(0.122)$ & & -0.022 & $(0.132)$ & $\mathrm{b}$ \\
\hline \multicolumn{13}{|l|}{ Spec 3} \\
\hline Spanish is primary language & -0.115 & $(0.026)$ & $* * *$ & -0.024 & $(0.024)$ & & -0.046 & $(0.026)$ & $*$ & -0.040 & $(0.026)$ & \\
\hline Lived in US $<5$ years & -0.057 & $(0.067)$ & & -0.089 & $(0.052)$ & & -0.024 & $(0.058)$ & & -0.111 & $(0.057)$ & $*$ \\
\hline Lived in US $>5$ years & 0.049 & $(0.052)$ & & -0.046 & $(0.043)$ & & 0.035 & $(0.042)$ & & -0.032 & $(0.044)$ & \\
\hline US born*Pct Spanish & 0.015 & $(0.092)$ & & -0.210 & $(0.086)$ & $* * a, b$ & -0.094 & $(0.076)$ & $\mathrm{b}$ & -0.129 & $(0.089)$ & $a, b$ \\
\hline Lived in US $<5 *$ Pct Spanish & -0.006 & $(0.141)$ & & 0.140 & $(0.121)$ & $\mathrm{a}$ & 0.132 & $(0.123)$ & $\mathrm{b}$ & 0.247 & $(0.133)$ & $* a$ \\
\hline Lived in US $>5 *$ Pct Spanish & -0.043 & $(0.086)$ & & -0.006 & $(0.074)$ & $\mathrm{b}$ & -0.054 & $(0.078)$ & & 0.044 & $(0.085)$ & $\mathrm{b}$ \\
\hline
\end{tabular}

Table Notes: Standard errors in parentheses. Stars indicate statistical difference of coefficient from zero; letters indicate statistical difference between coefficients. *** indicates significance at the .01 level, $* *$ at the .05 level and $*$ at the .10 level. Letters are included next to each element of the comparison pair, with a indicating a difference at the .01 level, ${ }^{b}$ indicating significantly different at the .05 level, and ${ }^{\mathrm{c}}$ indicating significantly different at the .10 level. 